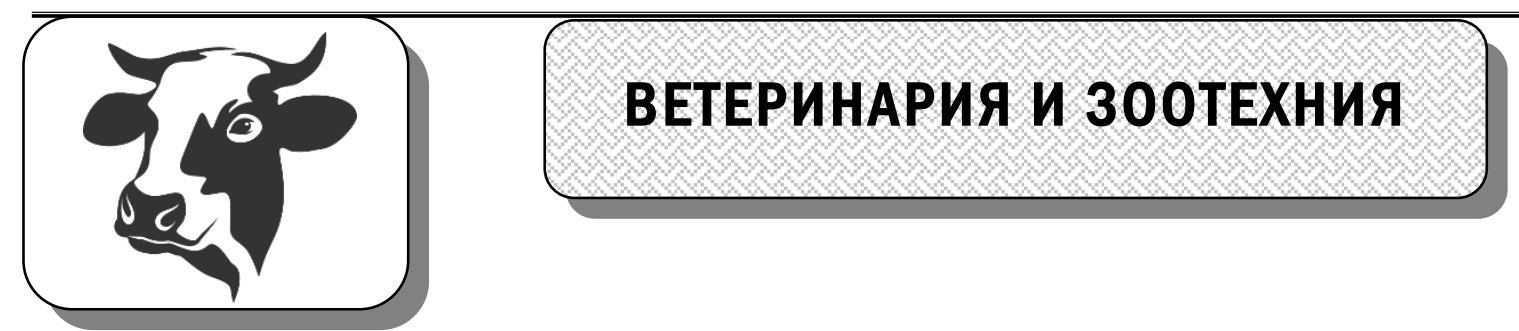

УДК 619:636.5:616.36

DOI: 10.36718/1819-4036-2019-11-39-45

Г.В. Сулайманова, Н.В. Донкова, А.А. Люто

\title{
ГИСТОЛОГИЧЕСКИЕ ОСОБЕННОСТИ ПЕЧЕНИ ЦЫПЛЯТ-БРОЙЛЕРОВ КРОССА АРБОР АЙКРЕЗ НА РАЗНЫХ ЭТАПАХ ПОСТЭМБРИОНАЛЬНОГО ОНТОГЕНЕЗА
}

\section{G.V. Sulaymanova, N.V. Donkova, A.A. Lyuto
HISTOLOGICAL FEATURES OF BROILERS' LIVER OF ARBOR IKREZ CROSS AT DIFFERENT STAGES OF POST-EMBRYONIC ONTOGENESIS

Сулайманова Г.В. - канд. ветеринар. наук, доц. каф. внутренних незаразных болезней, акушерства и физиологии сельскохозяйственных животных Красноярского государственного аграрного университета, г. Красноярск.

E-mail: sulaimanova5@yandex.ru

Донкова Н.В. - д-р ветеринар. наук, проф., зав. каф. анатомии, патанатомии и хирургии Красноярского государственного аграрного университета, г. Красноярск.

E-mail: dnv-23@mail.ru

Люто А.А. - канд. ветеринар. наук, науч. сотр. лаб. техногенных лесных экосистем ФИЦ КНЦ СО РАН, г. Красноярск.

E-mail: luto_a_a@rambler.ru

Цель исследования - изучить возрастную динамику гистологических особенностей печени цыплят-бройлеров кросса Арбор Айкрез. Материалом исследования послужила печень птицы 1-, 7-, 14-, 21-, 28-, 35- и 42-суточного возраста. Кусочки органа фриксировали в $10 \%$ растворе формалина. Общепринятьми методами готовили гистологические препараты и окрашивали их гематоксилином и эозином, а также Шиффф-йодной кислотой с метиленовым синим. Печень иыплят-бройлеров состоит из стромы и паренхимы. Наибольшее изменение структуры печени цыплят-бройлеров происходит в период с 1-х по 21-е сутки постэмбрионального онтогенеза. У суточных цыплят балочный рисунок печени не выражен, гепатоциты расположены хаотично, цито-
Sulaymanova G.V. - Cand. Veterinary Sci., Assoc. Prof., Chair of Internal Noncontagious Diseases, Obstetrics and Physiology of Farm Animals, Krasnoyarsk State Agrarian University, Krasnoyarsk.

E-mail: culaymanova@mail.ru

Donkova N.V. - Dr. Veterinary Sci., Prof., Head, Chair of Anatomy, Pathological Anatomy and Surgery, Krasnoyarsk State Agrarian University, Krasnoyarsk.

E-mail:dnv-23@mail.ru

Luto A.A. - Cand. Veterinary Sci., Staff Scientist, Lab. of Technogenic Forest Ecosystems, FRC KRC SB RAS, Krasnoyarsk.

E-mail: luto_a_a@rambler.ru

плазма пенистая, содержит жировые капли. На микропрепаратах печени просматриваются зоны формирования печеночных долек, в которых не видны кровеносные сосуды и желчевыводящие протоки, гепатоциты плотно прилегают друг к другу и вихреобразно закручиваются. К семисуточному возрасту в печени птицы видны печеночные балки и четче визуализируются границы гепатоцитов, в цитоплазме которых имеются единичные вакуоли. Гепатоциты птицы наиболее интенсивно pacmym до 14-суточного возраста, в дальнейшем их размеры достоверно не изменяются. На 21-е сутки постэмбрионального развития 8 ядрах гепатоцитов отчетливо видны ядрышки. В последующие возрастные периоды гистологчческая картина печени цыплят- 
бройлеров при использовании обзорных методов окраски не имеют принципиальных отличий. Таким образом, на 21-е сутки постэмбрионального онтогенеза у цыплят-бройлеров печень приобретает вид морфологически зрелого органа, а функциональная активность ее продолжает расти, о чем свидетельствует увеличение количества гликогена в гепатоцитах при окраске Шиффф-йодной кислотой.

Ключевые слова: печень, гистологические особенности, цыплята-бройлеры, кросс Арбор Айкрез.

The aim of the research was to study agerelated dynamics of histological characteristics of the liver of broiler chickens cross of Arbor lkrez. As the material of the research the liver of the birds 1-, 7-, 14-, 21-, 28-, 35-and 42-day age served. The pieces of the organ were fixed in $10 \%$ solution of formalin. Histological preparations were made by standard methods and painted with hematoxylin and eosin, and also Schiff-iodine acid with the methylene blue. Broiler chicken's liver consists of stroma and parenchyma. The largest changes in the structure of the liver occur from the first till the twenty-first day of postembryonic ontogenesis. In one day-aged chickens frame drawing of the liver is not expressed, hepatocytes are located chaotically; the cytoplasm is foamy, containing fatty drops. On micropreparations of liver zones of formation of hepatic lobes in which blood vessels and bile ducts are not visible are looked through, hepatocytes densely adjoin to each other and twisted like a whirlwind. To seven-days of age in a liver of a bird hepatic beams are visible and the borders of hepatocytes in which cytoplasm there are single vacuoles are more accurately visualized. Hepatocytes of the bird most intensively grow to 14-days of age, further their sizes authentically do not change. For the 21st day of post-embryonic development in kernels of hepatocytes small kernels are clearly visible. During subsequent age periods histological picture of the liver of broilers when using survey methods of coloring have no fundamental differences. Thus, for the 21st days of postembryonic ontogenesis in broilers the liver takes the form of morphologically mature body, and functional activity it continues to grow the increase in the quantity of glycogen in hepatocytes testifies to it under coloring with Schiff-iodine acid.
Keywords: liver, histological features, broiler chickens, Arbor Ikres cross.

Введение. Птицеводство является на сегодняшний день одной из самых эфффективных отраслей животноводства, обеспечивая население страны качественной диетической продукцией. Залог успеха современного птицеводства зависит от глубоких знаний морфологии и биологии птицы, содержащейся в «жестких» технологических условиях производства [12].

Морфологическая состоятельность ткани печени обеспечивает полноценное функционирование всего организма, так как именно этот орган способствует обезвреживанию и выведению эндогенных и экзогенных токсинов [4]. Печень самая крупная пищеварительная железа, которая выполняет множество функций: обмен белков, углеводов, жиров, витаминов, ферментов, регуляцию водного и минерального обмена, секрецию желчи, обезвреживание токсических веществ, фрагоцитирование микроорганизмов. В эмбриональный период печень является органом кроветворения $[1,3,9,10]$.

Морфогенезом печени кур в постнатальном онтогенезе занимались отечественные авторы И.В. Хохлов (2006) [13], Т.Н. Гришина (2010) [3], Л.И. Дроздова (2010) [4], А.Д. Ткачев (2010) [11], А.С. Копылов (2011) [5], В.В. Курилкин (2011) [7] и другие.

Имеющиеся в литературе данные о морфогенезе печени птицы носят разрозненный характер. Сведений о гистологическом строении печени цыплят-бройлеров кросса Арбор Айкрез на разных этапах постэмбрионального развития нами не найдено.

Цель исследования: изучение гистологических особенностей печени цыплят-бройлеров кросса Арбор Айкрез на разных этапах постэмбрионального онтогенеза.

Объект, материалы и методы исследования. Объектом исследования послужила печень цыплят-бройлеров кросса Арбор Айкрез. Были исследованы 70 органов, по 10 от цыплят каждой возрастной группы: суточных, 7-, 14-, 21-, 28-, 35- и 42-суточных. После декапитации цыплят проводили обескровливание, вскрывали брюшную полость, извлекали печень и фиксировали кусочки органа в $10 \%$ растворе нейтрального формалина. Общепринятыми методами готовили гистологические препараты и 
окрашивали их гематоксилином и эозином, а также Шиффф-йодной кислотой с метиленовым синим [6]. Гистологические препараты просматривали под микроскопом при объективе 8x, 40х, 90x. Морфометрические измерения гепатоцитов и их ядер проводили с помощью программы Cito 2.0. Статистическую обработку полученных результатов проводили с использованием t-критерия Стьюдента.

Результаты исследования. При проведении исследования мы выявили, что печень цыплят-бройлеров кросса Арбор Айкрез является типичным паренхиматозным органом, состоящим из паренхимы и стромы. Снаружи печень покрыта серозной оболочкой, состоящей из однослойного плоского эпителия, под которым расположена тонкая прослойка соединительной ткани - капсула. У цыплят-бройлеров строма, образованная соединительной тканью, развита достаточно слабо и встречается лишь по перифрерии органа, где формирует капсулу, а также в области портальных 30н. Междольковые соединительнотканные перегородки не выявляются, в связи с чем печень цыплят не обладает выраженным дольчатым строением.

Основную массу клеточных элементов печени у цыплят-бройлеров составляют гепатоциты, являющиеся паренхиматозными элементами органа. В печени птицы суточного возраста гепатоциты расположены вокруг центральной вены хаотично (рис. 1), печеночные трабекулы не просматриваются. Ядра гепатоцитов расположены в основном эксцентрично, цитоплазма гепатоцитов пенистая, в ней видны жировые капли, наличие которых в печени суточных цыплят является нормой. Это обусловлено тем, что куриный эмбрион с 18-х суток переходит на внутрикишечное питание желтком [2], в котором содержится до 33 \% жира [1]. В печени суточных цыплят имеются зоны формирования печеночных долек, где не видны сосуды и желчевыводящие протоки, гепатоциты, не имеющие четких границ, плотно прилегают к друг другу и вихреобразно закручиваются. В зоне плохо дифференцированных клеток отмечается повышенная базофилия цитоплазмы (см. рис. 1), что может свидетельствовать о происходящей в ней интенсивном белковом синтезе.

В печени 7-суточных цыплят при окраске гематоксилином и эозином отчетливо видны границы гепатоцитов, сами клетки имеют в основ- ном полигональную, реже овальную и еще реже округлую форму. Цитоплазма гепатоцитов окрашена слабо оксифильно, в ней видны единичные вакуоли и множественные мелкодисперстные включения, в центре клетки, а иногда эксцентрично визуализируется ядро. Вокруг округлой, реже овальной центральной вены, которая имеет размер больше, чем у суточных цыплят, ряды печеночных клеток располагаются радиально, а в центральной и периферической части долек этот порядок нарушается. Трабекулы, или так называемые пластинки, состоят из двух рядов печеночных клеток, между которыми расположены капилляры синусоидного типа, образующие анастомозирующую сеть. На тангенциальных срезах радиального строения печеночных трабекул не видно.

В печени 14-суточных цыплят печеночные трабекулы приобретают более ровный вид (рис. 2), особенно в перивенулярной области, по мере приближения к перипотальной зоне стройность их рядов теряется. Ядра гепатоцитов располагаются в основном в центре, а не эксцентрично, как у суточной птицы. Печеночные балки в печени цыплят отчетливо разделены широкими просветами капилляров, иногда в них видны ядерные эритроциты. Пенистость цитоплазмы гепатоцитов у цыплят данной возрастной группы уже не видна. В перипортальной области встречаются лимфоидные инфильтраты. При измерении морфометрических показателей печени птицы нами выяснено, что площадь гепатоцитов у цыплят-бройлеров кросса Арбор Айкрез достоверно увеличивается только до 14суточного возраста.

Гистологическая картина печени цыплят 21суточного возраста похожа на картину печени 14-суточной птицы (см. рис. 2), только в ядрах гепатоцитов отчетливее видны от одного до трех ядрышек, что говорит о большей диффреренциации клеток. Кроме того, у 21-дневных цыплят-бройлеров на гистологических препаратах печени печеночные балки становятся более ровными, даже в перивенулярной зоне, лимфоидные скопления приобретают большие размеры. На 28-е, 35-е и 42-е сутки постэмбрионального онтогенеза печень цыплят-бройлеров кросса Арбор Айкрез при использовании обзорных методов окраски не имеют принципиальных отличий от морфологической картины печени цыплят 21-суточного возраста (рис. 3). 


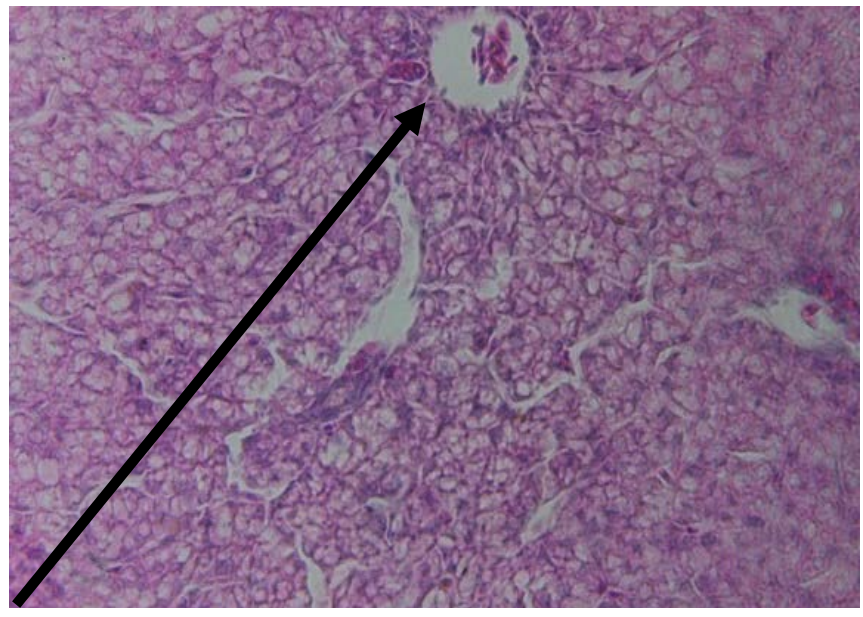

Puc. 1. Печень цыпленка суточного возраста. Центральная вена (отмечена стрелкой). Окраска гематоксилином и эозином. Ув. об. ×40

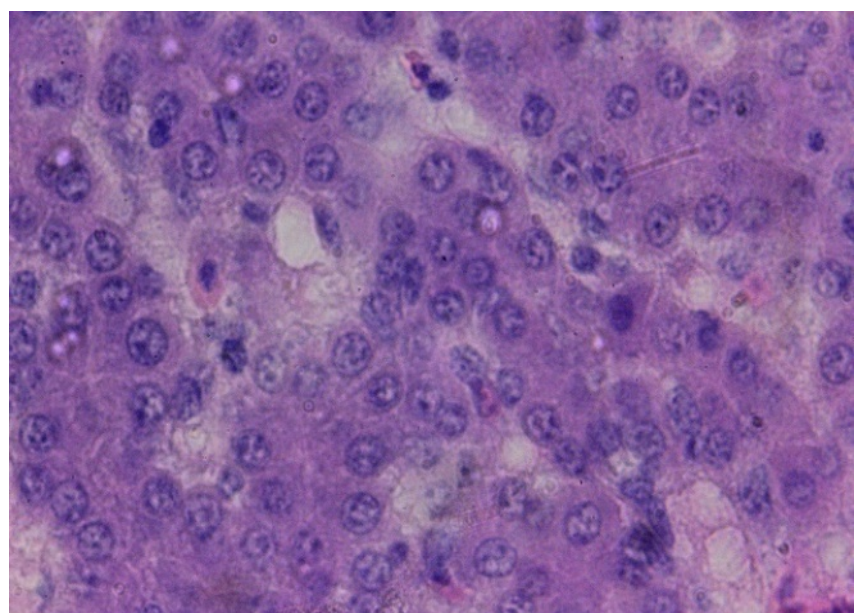

Puc. 2. Печень цыпленка, 21-е сут. Окраска гематоксилином и эозином. Ув. об. ×90

На гистологическом препарате печени 35суточной птицы отчетливо видны очаги лимфоидной инфильтрации (рис. 4), которые локализованы преимущественно около сосудов печени и характеризуются разнообразием состава. Наибольшим количеством представлены клетки лимфоидного ряда - большие и малые лимфоциты, реже встречаются моноциты, и очень редко - плазмоциты. Достаточно много клеток, напоминающих по структуре клетки предшественников лимфоцитов, которые характеризуются большим размером, окрашенной цитоплазмой, крупным, неровным светлоокрашенным ядром, содержащим многочисленные ядрышки (5 и более). Считается, что лимфоидные скопления являются вариантом нормы для птицы, они описа- ны рядом авторов [7, 13]. Лимфоидные скопления создают иммунную защиту организма и способны противостоять патогенным воздействиям. На микропрепарате печени 35-суточной птицы видно, что лимфоидный инфильтрат значительно отличается от паренхимы печени по содержанию гликогена (см. рис. 4). В клетках инфильтрата накопления гликогена полностью отсутствуют, при этом цитоплазма выглядит пустой за счет ее непрокрашенного содержимого. Граница между инфильтратом и гепатоцитами выделяется отчетливо. При окраске Шиффр-йодной кислотой у цыплят более старшего возраста отмечается значительное накопление гликогена в цитоплазме гепатоцитов, что свидетельствует о росте функциональной активности клеток (рис. 5, 6). 


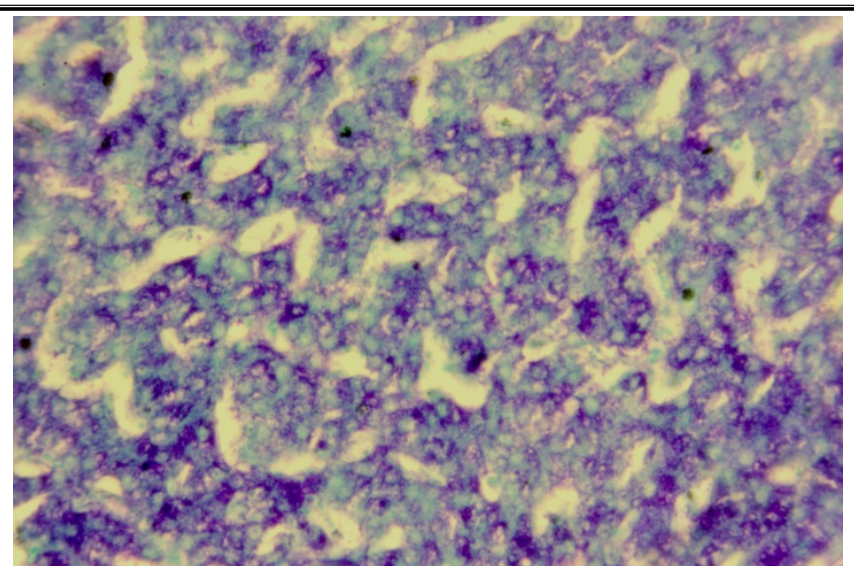

Puс. 3. Печень 28-суточных цыплят. Окраска Шиффф-йодной кислотой, с докраской метиловым зеленым. Ув. об. х 40

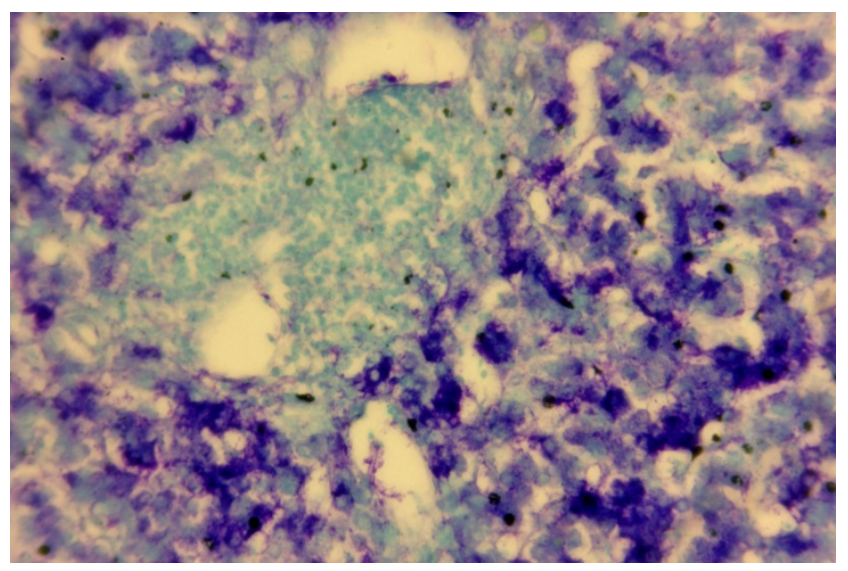

Pис. 4. Печень 35-суточных цыплят, лимфоидный инфильтрат (отмечен стрелкой). Окраска Шифрф-йодной кислотой, с докраской метиловым зеленым. Ув. об. х 40

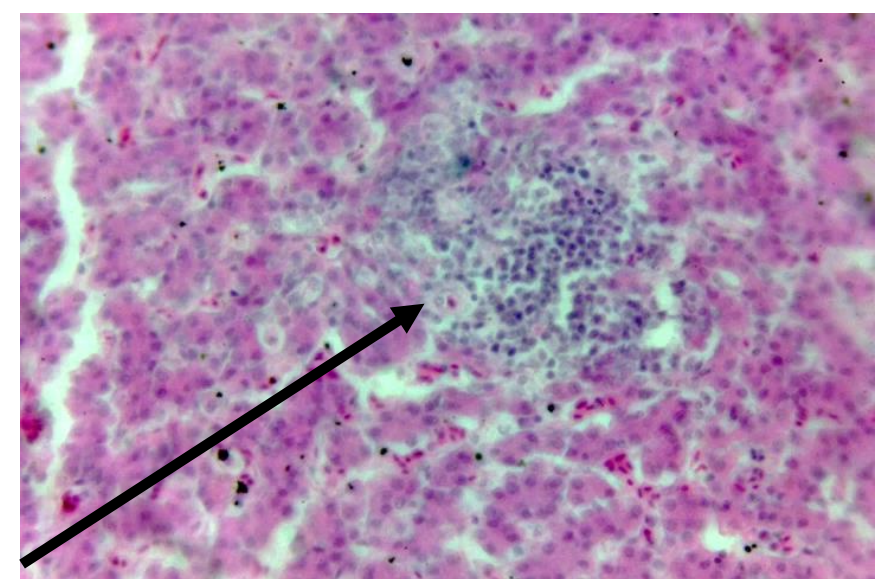

Рис. 5. Печень цыпленка, 35-е сут, инфильтрат (отмечен стрелкой). Окраска гематоксилином и эозином. Ув. об. х 40 


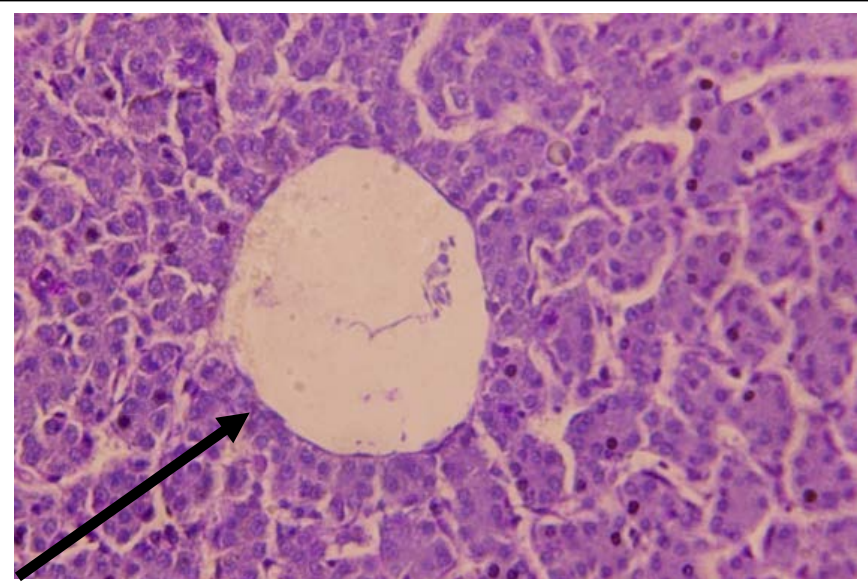

Pис. 6. Печень цыпленка, 42-е сут, окраска гематоксилином и эозином. Ув. об. х 40

Заключение. Наибольшее изменение структуры печени цыплят-бройлеров кросса Арбор Айкрез происходит в период с 1-х по 21-е сутки постэмбрионального онтогенеза. В 1-е сутки формируются классические дольки, к 7-м суткам отчетливо визуализируются печеночные балки. До 14суточного возраста у цыплят-бройлеров отмечали наиболее интенсивный рост гепатоцитов, на 21-е сутки в ядрах гепатоцитов отчетливее визуализируются от одного до трех ядрышек, что характерно для морфологически зрелой клетки. Таким образом, на 21-е сутки постэмбрионального онтогенеза у цыплят-бройлеров кросса Арбор Айкрез печень приобретает вид морфологически зрелого органа, в то время как функциональная активность ее продолжает расти, о чем свидетельствует увеличение количества гликогена в гепатоцитах при окраске Шиффф-йодной кислотой.

\section{Литература}

1. Бессарабов Б.Ф., Алексеева С.А., Клетикова Л.В. Этиопатогенез, диагностика и профилактика нарушений обмена веществ у сельскохозяйственной птицы. - М.: 300медлит, 2011. - 296 с.

2. Вракин В.Ф., Сидорова М.Ф. Морфология сельскохозяйственных животных (анатомия с основами цитологии, эмбриологии и гистологии). - М.: Агропромиздат, 1991. - 528 с.

3. Гришина Д.Ю. Морфология печени цыплят бройлеров в раннем постнатальном онтогенезе: дис. ... канд. биол. наук.- Самара, 2009. - 128 c.

4. Дроздова Л.И., Кундрюкова У.И. Печень птицы - живая лаборатория оценки качества кормления и содержания // Аграрный вестник Урала. - 2010. - № 5 (71). - С. 68-70.

5. Копылов А.С. Морфология печени бройлеров кросса Смена-7 в норме и при применении «Гамавита»: автореф. дис. ... канд. биол. наук. - Саранск, 2011. - 24 с.

6. Коржевский Д.Э. Гиляров А.В. Основы гистологической техники. - СПб.: СпецЛит, 2010. - 95 c.

7. Курилкин В.В. Морфоорункциональные показатели печени кур в постэмбриональном онтогенезе: автореср. дис. ... канд. ветеринар. наук. - М., 2011. - 18 с.

8. Сапин М.P. Индивидуальная изменчивость иммунных структур и иммунодефицит // Морфология. - 1996. - Т.109, № 2. - С. 88.

9. Селянский В.М. Анатомия и фиизиология сельскохозяйственной птицы. - М.: Колос, 1980. - 272 c.

10. Сулайманова Г.В., Донкова Н.В. Морфометрические особенности печени кур кросса Арбор Айкрес // Вестн. КрасГАУ. 2019. - № 4. - С. 75-80.

11. Ткачев Д.А. Постнатальный морфогенез печени у кур кросса Иза-Браун: автореф. дис. ... канд. вет. наук. - Брянск, 2007. C. 21.

12. Турицына Е.Г. Иммунодесрициты птиц: этиология, патогенез, морфологическая диагностика, способы коррекции / Краснояр. гос. аграрн. ун-т. - Красноярск, 2010. - 208 с.

13. Хохлов И.В. Морфология изменения печени кур // Птицеводство. - 2006. - № 3. C. 27-30. 


\section{Literatura}

1. Bessarabov B.F., Alekseeva S.A., Kletikova L.V. Etiopatogenez, diagnostika i profilaktika narushenij obmena veshchestv u sel'skohozyajstvennoj pticy. - M.: Zoomedlit, 2011. - $296 \mathrm{~s}$.

2. Vrakin V.F., Sidorova M.F. Morfologiya sel'skohozyajstvennyh zhivotnyh (anatomiya s osnovami citologii, embriologii i gistologii). M.: Agropromizdat, 1991. - $528 \mathrm{~s}$.

3. Grishina D.YU. Morfologiya pecheni cyplyat brojlerov v rannem postnatal'nom ontogeneze: dis. ... kand. biol. nauk.- Samara, 2009. - 128 s.

4. Drozdova L.I., Kundryukova U.I. Pechen' pticy zhivaya laboratoriya ocenki kachestva kormleniya i soderzhaniya // Agrarnyj vestnik Urala. - 2010. - № 5 (71). - S. 68-70.

5. Kopylov A.S. Morfologiya pecheni brojlerov krossa Smena-7 v norme i pri primenenii Gamavita: avtoref. dis. ... kand. biol. nauk. Saransk, 2011. - 24 s.

6. Korzhevskij D.E. Gilyarov A.V. Osnovy gistologicheskoj tekhniki. - SPb.: SpecLit, 2010. - 95 s.
7. Kurilkin V.V. Morfofunkcional'nye pokazateli pecheni kur v postembrional'nom ontogeneze: avtoref. dis. ... kand. veterinar. nauk. - M., 2011. - $18 \mathrm{~s}$.

8. Sapin M.R. Individual'naya izmenchivost' immunnyh struktur i immunodeficit // Morfologiya. - 1996. - T. 109, № 2. - S. 88.

9. Selyanskij V.M. Anatomiya i fiziologiya sel'skohozyajstvennoj pticy. - M.: Kolos, 1980. - $272 \mathrm{c}$.

10. Sulajmanova G.V., Donkova N.V. Morfometricheskie osobennosti pecheni kur krossa «Arbor Ajkres» // Vestn. KrasGAU. 2019. - № 4. - S. 75-80.

11. Tkachev D.A. Postnatal'nyj morfogenez pecheni u kur krossa Iza-Braun: avtoref. dis. ...kand. vet. nauk. - Bryansk, 2007. - S. 21.

12. Turicyna E.G. Immunodeficity ptic: etiologiya, patogenez, morfologicheskaya diagnostika, sposoby korrekcii / Krasnoyar. gos. agrarn. un-t. - Krasnoyarsk, 2010. - $208 \mathrm{~s}$.

13. Hohlov I.V. Morfologiya izmeneniya pecheni kur // Pticevodstvo. - 2006. - № 3. S. 27-30. 